\title{
Structural analysis of RF sputtered Ge-Sb-Se thin films by Raman and X-ray photoelectron spectroscopies
}

\author{
Baudet E. ${ }^{1}$, Cardinaud C. ${ }^{2}$, Girard A. ${ }^{2}$, Rinnert Emmanuel ${ }^{3}$, Michel K. ${ }^{4}$, Bureau B. ${ }^{1}$, Nazabal V. ${ }^{1,}$ \\ ${ }^{1}$ Univ Rennes 1, Inst Sci Chini Rennes, UMR CNRS 6226, Equipe Verres \& Ceram, F-35042 Rennes, \\ France. \\ 2 Univ Nantes, CNRS, Inst Mat Jean Rouxel IMN, UMR 6502, F-44322 Nantes 3, France. \\ 3 IFREMER, Lab Detect Capteurs \& Mesures, Dept Rech \& Dev Technol, F-29280 Plouzane, France. \\ ${ }^{4}$ Bur Rech Geol \& Minieres, Direct Eau Environm \& Ecotechnol, Unite BioGeochim Environm \& Qualite \\ Eau, F-45060 Orleans, France.
}

*Corresponding author : Virginie Nazabal, email address : virginie.nazabal@univ-rennes1.fr

\begin{abstract}
:
Chalcogenide thin films (GeSe2)100 - x(Sb2Se3)x (with $x=10$ and 50) were deposited by Radiofrequency (RF) magnetron sputtering. In order to study the impact of Ar pressure on the structure and the composition of selenide thin films structural properties of thin films and targets were investigated by means of Raman scattering spectroscopy and X-ray photoelectron spectroscopy (XPS). Under low pressure ( 5 - 10- $3 \mathrm{mbar}$ ), the increase of wrong bonds like $\mathrm{Ge}(\mathrm{Sb})-\mathrm{Ge}(\mathrm{Sb})$ was confirmed by Raman and also XPS for both composition. The observed structural changes with Ar pressure are linked with modification of the composition of the selenide films analyzed by EDS and XPS. Furthermore for higher Ar pressure (5 - 10- 2 mbar), RF sputtered thin film and target structure present a great similarity. These differences driven by Ar pressure modification are probably related to distinctive sputtering rate and mean free path of the particles ejected from target for the different Ar pressures.
\end{abstract}

\section{Highlights}

$\left(\mathrm{GeSe}_{2}\right)_{100-\mathrm{x}}\left(\mathrm{Sb}_{2} \mathrm{Se}_{3}\right)_{\mathrm{x}}$ thin films were deposited by RF magnetron sputtering. Structural properties of thin films were studied by Raman spectroscopy and X-ray photoelectron spectroscopy (XPS). Proportion of $\mathrm{M}-\mathrm{M}$ bonds $(\mathrm{M}=\mathrm{Ge}, \mathrm{Sb})$ decreases for higher Ar pressure. Thin films structure and composition are closer to the glass target for higher Ar pressure.

Keywords: Chalcogenide glass, Thin films, Radio-frequency magnetron sputtering, Raman spectroscopy, X-ray photoelectron spectroscopy, Structure 


\section{Introduction}

Chalcogenide glasses, based on $\mathrm{S}$, Se or Te element in combination with a suitable element from $13^{\text {th }}(\mathrm{Ga}, \mathrm{In}), 14^{\text {th }}(\mathrm{Si}, \mathrm{Ge})$ or $15^{\text {th }}(\mathrm{As}$, Sb) group of the periodical system, are an important class of amorphous materials appropriate for many applications such as sensors [1-4], optical waveguide for integrated optic [5-7] or lens for IR camera [8]. Optical properties of binary chalcogenide glasses such as $\mathrm{As}_{2} \mathrm{~S}_{3}$ or $\mathrm{As}_{2} \mathrm{Se}_{3}$ [9-11] and ternary systems like Ge-As-Se [12, 13] have been widely studied.

These glasses offer an undeniable chemical stability and the ternary system is one of the largest available glassy domains with chalcogenide compounds. However, elemental arsenic can be disputed owing to its toxicity. Hence other systems, with promising characteristics and environmentally acceptable, were studied [14]. Ge-Sb-Se system is one of them, as this ternary system presents obvious advantages for optical applications: it benefits from a wide transparency in the infrared range (2-15 $\mu \mathrm{m})$, a high refractive index (between 2.5 and 2.9) and a shaping ability that enables its use as fibers or thin films. Chalcogenide thin films can be synthesized from a solid target according different PVD methods: thermal evaporation [15-18], RF magnetron sputtering [15, 19-21] or pulsed laser deposition $[19,22]$. In recent years, Ge-Sb-Se thin films and waveguides proved to offer a great potential for biological and chemical sensors [20, 23-25].

The optical properties and structure of chalcogenide glasses of pseudo-binary system with nominal composition $\left(\mathrm{GeSe}_{2}\right)_{100-\mathrm{x}}\left(\mathrm{Sb}_{2} \mathrm{Se}_{3}\right)_{\mathrm{x}}$, where $\mathrm{x}$ varies from 5 to 70 , have lately been characterized [26, 27]. It reveals a progressive change when increasing the $\mathrm{Sb}_{2} \mathrm{Se}_{3}$ content in the system, first favoring edge-shared $\left[\mathrm{GeSe}_{4 / 2}\right]$ edge-linked entities. Sb-rich compositions contain more Sb-Sb, Ge-Ge and Se-Se structural motifs. In this work, we focused our attention on two compositions of this system: $\mathrm{Ge}_{28.1} \mathrm{Sb}_{6.3} \mathrm{Se}_{65.6}(\mathrm{Se}-2)$ and $\mathrm{Ge}_{12.5} \mathrm{Sb}_{25} \mathrm{Se}_{62.5}$ (Se-6), and more specifically on thin films synthesized via RF magnetron sputtering. 
The aim of this work is to study the structure of RF chalcogenide thin films with the nominal composition $\mathrm{Ge}_{28.1} \mathrm{Sb}_{6.3} \mathrm{Se}_{65.6}\left(\mathrm{Se}_{2}\right)$ and $\mathrm{Ge}_{12.5} \mathrm{Sb}_{25} \mathrm{Se}_{62.5}\left(\mathrm{Se}_{-}\right.$ 6) deposited under various Ar pressures: $5.10^{-3}, 7.5 .10^{-3}, 1.10^{-2}$ and $5.10^{-2}$ mbar. One of the most influencing parameters of RF magnetron deposition of selenide films is the Ar pressure controlling the film growth, the microstructure, the stoichiometric conformity, the roughness and also the structure [28]. The structure of sputtered thin films, analyzed by X-ray photoelectron spectroscopy and Raman spectroscopy, was studied and compared to the chalcogenide targets in order to investigate the influence of the Ar pressure.

\section{Material and experimental methods}

Chalcogenide glass targets with composition $\left(\mathrm{GeSe}_{2}\right)_{100-\mathrm{x}}\left(\mathrm{Sb}_{2} \mathrm{Se}_{3}\right)_{\mathrm{x}}(\mathrm{x}=10$ and $\mathrm{x}=50$ named respectively Se-2 and Se-6) were prepared using the conventional melting and quenching method. Glasses were synthesized from high purity (5N) commercial elements (Ge, Sb, Se). Selenium was pre-purified by static distillation. Elements were weighted in appropriate amount, introduced in a silica glass ampoule under vacuum and then sealed. Then the elements were melted at $850^{\circ} \mathrm{C}$ in a rocking furnace, quenched in water and the product was annealed at a temperature close to its glass transition temperature (Tg) i.e. $\sim 330$ and $\sim 205^{\circ} \mathrm{C}$ respectively for $\mathrm{Ge}_{28.1} \mathrm{Sb}_{6.3} \mathrm{Se}_{65.6}(\mathrm{Se}-2)$ and $\mathrm{Ge}_{12.5} \mathrm{Sb}_{25} \mathrm{Se}_{62.5}$ (Se-6). Chalcogenide glass targets with a diameter of $50 \mathrm{~mm}$ and a thickness of $3.5 \mathrm{~mm}$ were obtained after cutting and polishing of the glass rod. These chalcogenide glasses were used as sputtering targets for thin films deposition. Chalcogenide thin films Se-2 and Se-6 were deposited on silicon substrates at low RF magnetron sputtering considering the insulator character of the targets. In order to study influence of argon pressure on thin films structure, four argon working pressures were applied for the sputtering process: $5.10^{-3}, 7.5 .10^{-3}$, $1.10^{-2}$ and $5.10^{-2}$ mbar. The sputtering power was respectively $20 \mathrm{~W}$ and $10 \mathrm{~W}$ for Se-2 and Se-6 because of fragility of Se- 6 target. Time deposition was chosen to obtain similar thicknesses for all thin films i.e. $2.3 \mu \mathrm{m}$. An off-axis substrate rotation was operated during the deposition process and silicon 
substrates were positioned at the target to substrate distance of $50 \mathrm{~mm}$. After synthesis, and to avoid formation of surface oxides, all samples were kept under inert atmosphere until they were analyzed. The thickness of the films is evaluated by UV-near IR spectrophotometry.

Raman scattering spectra of Se-2 and Se-6 thin films and glass targets were collected at room temperature under $785 \mathrm{~nm}$ laser excitation with a LabRam HR800 (Horiba Jobin-Yvon) spectrometer coupled to Olympus x100 microscope. To avoid photoinduced phenomena, optical density filters have been selected to reduce the laser power focused on the samples.

X-ray Photoelectron Spectroscopy was used to characterize the top surface of Se-2 and Se-6 thin films. Spectra were collected using a Kratos Axis Ultra X-ray photoelectron spectrometer using monochromatic Al Ka X-rays (1486.6 eV, $15 \mathrm{kV}-20 \mathrm{~mA})$. Survey scans were acquired at a pass energy of 80 $\mathrm{eV}$, and high resolution spectra of the Ge $2 \mathrm{p}_{3 / 2}, \mathrm{Sb} 3 \mathrm{~d}, \mathrm{Se} 3 \mathrm{~d}, \mathrm{Sb} 4 \mathrm{~d}$ and Ge $3 \mathrm{~d}$ core levels were acquired at a pass energy of $20 \mathrm{eV}$. Surface charging from photoelectron emission was neutralized using the built-in system, which combines a low energy (2.5 V extraction voltage) electron flood gun and the spectrometer magnetic lens. The analysis was made at 0,60 and $70^{\circ}$ take off angles with respect to the normal to the sample surface. The binding energy scale was calibrated using a commercial chalcogenide glass $\mathrm{Ge}_{25} \mathrm{Sb}_{10} \mathrm{Se}_{65}$ (Schott) using Se 3d core-level photoelectron peak as reference. Data analysis of the core levels (Ge 2p $\mathrm{p}_{3 / 2}, \mathrm{Sb} 3 \mathrm{~d}-\mathrm{O}$ 1s, Se 3d, Sb 4d - Ge 3d) was conducted with standard CASA-XPS software. Each 3d (Ge, Sb, Se) and 4d (Sb) core-level spectrum is constituted of $3 \mathrm{~d}_{5 / 2}, 3 \mathrm{~d}_{3 / 2}$ and $4 \mathrm{~d}_{5 / 2}, 4 \mathrm{~d}_{3 / 2}$ spin orbits doublets.

The chemical composition of $\mathrm{Ge}_{28.1} \mathrm{Sb}_{6.3} \mathrm{Se}_{65.6}(\mathrm{Se}-2)$ and $\mathrm{Ge}_{12.5} \mathrm{Sb}_{25} \mathrm{Se}_{62.5}$ (Se-6) thin films and glass targets was measured using a scanning electron microscope with an energy-dispersive X-ray analyzer (EDS, JSM 6400-OXFORD Link INCA). Atomic percentage of each element ( $\pm 0.5 \%$ and $\pm 1 \%$, for targets and films respectively) was determined using the LLL lines of Ge, Sb and Se at $20 \mathrm{kV}$ for glass targets and at $10 \mathrm{kV}$ for thin films. 


\section{Results and discussion}

In this study, XPS and Raman spectroscopy enabled structural investigation of RF Ge-Sb-Se sputtered thin films for different Ar pressure. Previous XPS studies have described the structure of $\mathrm{Sb}_{\mathrm{x}} \mathrm{Ge}_{40-\mathrm{x}} \mathrm{Se}_{60}$ and $\mathrm{Ge}_{\mathrm{x}} \mathrm{Sb}_{10} \mathrm{Se}_{90-\mathrm{x}}$ selenide glasses [29, 30]. XPS and Raman analyses were also proposed for PVD films of sputtered or evaporated thin films deposited from $\mathrm{Ge}_{28} \mathrm{Sb}_{12} \mathrm{Se}_{60}$ or $\mathrm{Ge}_{25} \mathrm{Sb}_{10} \mathrm{Se}_{65}$ [20, 31]. XPS analysis of Ge $\mathrm{Sb}_{10} \mathrm{Se}_{90-\mathrm{x}}$ glasses reveals the presence of Setrimers and Se-Se-Ge(Sb) simply for Se-rich composition and the presence of Sb-Sb and Ge-Ge bonds only for Se-deficient composition [30]. In contrary for $\mathrm{Sb}_{\mathrm{x}} \mathrm{Ge}_{40-\mathrm{x}} \mathrm{Se}_{60}$ glasses (Se-deficient glasses) investigated by XPS, the authors reported the formation of deformed Ge-based tetrahedra and Sb-based pyramids where Se atoms are substituted by at least one Ge or Sb cation while unexpected Se-Se dimers are present in all the investigated compositions[29]. It was also proposed that the $\mathrm{Ge}_{28} \mathrm{Sb}_{12} \mathrm{Se}_{60} \mathrm{Se}$-deficient films have greater proportion of $\left[\mathrm{Ge}_{2} \mathrm{Se}_{6 / 2}\right]$, $\left[\mathrm{Sb}_{2} \mathrm{Se} \mathrm{S}_{4 / 2}\right]$ units and Se-Se bonds compared to bulk counterpart [31]. For the sputtered films based on $\mathrm{Ge}_{25} \mathrm{Sb}_{10} \mathrm{Se}_{65}$ deposited at two different pressure, the presence of (Ge, $\mathrm{Sb}$ )-Sb-Se ${ }_{2}$ and (Ge, $\mathrm{Sb}$ )-Ge-Se ${ }_{3} \mathrm{Species}$ is observed in agreement with the Raman spectra recorded for the two films [20]. The M-M bonds are in higher proportion in case of the film deposited at lower pressure. Their formation is mainly due to the fact that the sputtered films are Se-deficient especially for lower pressure and Se-Se-(Sb, Ge) entities are also reported.

In order to compare the structure of sputtered thin films $\left(\mathrm{GeSe}_{2}\right)_{100-\mathrm{x}}\left(\mathrm{Sb}_{2} \mathrm{Se}_{3}\right)_{\mathrm{x}}$, Raman spectra of chalcogenide targets with the nominal composition $\mathrm{Ge}_{28.1} \mathrm{Sb}_{6.3} \mathrm{Se}_{65.6}(\mathrm{Se}-2)$ and $\mathrm{Ge}_{12.5} \mathrm{Sb}_{25} \mathrm{Se}_{62.5}(\mathrm{Se}-6)$ and sputtered thin films deposited under different Ar pressure $\left(5.10^{-3}, 7.5 .10^{-3}, 1.10^{-2}\right.$ and $5.10^{-2}$ mbar $)$ were recorded and shown in Fig. 1. Raman studies of bulk $\left(\mathrm{GeSe}_{2}\right)_{100-\mathrm{x}}\left(\mathrm{Sb}_{2} \mathrm{Se}_{3}\right)_{\mathrm{x}}$ with $\mathrm{x}$ ranges from 5 to 70 have been reported [26] and present a Raman spectra with two main peaks at $\sim 200$ and $215 \mathrm{~cm}^{-1}$ attributed respectively to $\mathrm{A}_{1}$ symmetric stretching mode of corner linked [GeSe $4 / 2$ ] tetrahedra [32-36] and to $\mathrm{A}_{1}{ }^{\mathrm{c}}$ breathing vibration mode (also named companion mode) but more frequently to vibration modes of [GeSe $4 / 2]$ tetrahedra connected by edges [33-37]. An 
addition of antimony in the glassy matrix leads to changes in the network. A slight increase of [ $\mathrm{GeSe}_{4 / 2}$ ] tetrahedra connected by edges is obtained compared to those connected by corners. Additionally, the band centered at $\sim 170 \mathrm{~cm}^{-1}$ which can be connected with stretching modes of Ge-Ge bonds in [Ge $\left.\mathrm{Se}_{6 / 2}\right]$ entities $[36,38,39]$ decreases with the addition of Sb. At $\sim 250-330 \mathrm{~cm}^{-1}$, a peak with a low and broad intensity can be observed due to the overlap of several contribution: i) Se-Se stretching mode at chains, outrigger or rings $\left(\sim 235-245 \mathrm{~cm}^{-1}\right)$ [33], ii) Se-Se bonds vibration from $\mathrm{Se}_{\mathrm{n}}$ chains and [GeSe $\mathrm{Ge}_{4 / 2}$ corner linked (dimers, small chains) $\left(\sim 265 \mathrm{~cm}^{-1}\right)[32,33,37,39-41]$, iii) Ge-Ge bonds vibrations in $\mathrm{Ge}_{\mathrm{x}} \mathrm{GeSe}_{4-\mathrm{x}}$ structural units $(\mathrm{x}=1,2,3,4)$ similarly to amorphous germanium $\left(\sim 270 \mathrm{~cm}^{-1}\right)$ and finally, $\mathrm{F}_{2}$ asymmetric vibration modes of [ $\left.\mathrm{GeSe}_{4 / 2}\right]$ tetrahedra $\left(\sim 285-300 \mathrm{~cm}^{-1}\right)[19,33,42]$. Olivier et al. [26] demonstrated that when $\mathrm{Sb}_{2} \mathrm{Se}_{3}$ content is higher than $30 \%$, there is balance between $\left[\mathrm{SbSe}_{3 / 2}\right]$ pyramids and $\left[\mathrm{GeSe}_{4 / 2}\right]$ tetrahedra. Finally, for higher $\mathrm{Sb}$ content, as the nominal composition $\mathrm{Ge}_{12.5} \mathrm{Sb}_{25} \mathrm{Se}_{62.5}(\mathrm{Se}-6),\left(\mathrm{Se}_{2}\right) \mathrm{Sb}-\mathrm{Sb}\left(\mathrm{Se}_{2}\right)$ structural motifs seem to be present at $160 \mathrm{~cm}^{-1}$.

For Se-2 sputtered thin films with $\mathrm{Ge}_{28.1} \mathrm{Sb}_{6.3} \mathrm{Se}_{65.6}$ nominal composition (Fig. 1a), the two main peaks at $\sim 200$ and $\sim 215 \mathrm{~cm}^{-1}$ usually attributed to $\left[\mathrm{GeSe}_{4 / 2}\right]$ tetrahedra connected by corners and by edges are observed. Raman spectra present also a band peak at $\sim 175 \mathrm{~cm}^{-1}$, which mainly corresponds to GeGe bonds in $\mathrm{Ge}_{2} \mathrm{Se}_{6 / 2}$ species. Finally, the weak and broad band attributed to Se-Se bond and [ $\left.\mathrm{GeSe}_{4 / 2}\right]$ tetrahedra vibrations $\left(\sim 235-300 \mathrm{~cm}^{-1}\right)$ is also observed. Regarding Ar pressure influence, the intensity of band at $\sim 215 \mathrm{~cm}^{-1}$ increases when increasing Ar pressure, therefore there is an increase of [GeSe ${ }_{4 / 2}$ ] tetrahedra connected by edges compared to $\left[\mathrm{GeSe}_{4 / 2}\right.$ ] tetrahedra connected by corners (Fig. 2a). Raman spectra of Se-2 thin films shows also that the band at $\sim 175 \mathrm{~cm}^{-1}$, corresponding to $\mathrm{Ge}-\mathrm{Ge}$ in $\mathrm{Ge}_{2} \mathrm{Se}_{6 / 2}$, becomes less intense with the increase of Ar pressure but remains still higher than its bulk counterpart. While Raman intensity at $\sim 265 \mathrm{~cm}^{-1}$ increases for Ar pressure of about $5.10^{-2}$ mbar related to Se-Se bond in dimers or small chains linking [GeSe ${ }_{4 / 2}$ t tetrahedra. Thus, a low Ar pressure leads to the formation of $\mathrm{Ge}_{2} \mathrm{Se}_{6 / 2}$ entities favored over [ $\mathrm{GeSe}_{4 / 2}$ ] tetrahedral with a deficit in Se (in comparison with the stoichiometric composition of the target) as it can be seen in Table 1. But even for low Ar pressure, it can be noticed the presence of a weak band at $138-145 \mathrm{~cm}^{-1}$ often associated to Se-Se bending vibration modes. To conclude, for higher Ar pressure, structure of Se- 2 chalcogenide thin films is closer to the target, i.e. a glassy 
network composed mainly of $\left[\mathrm{GeSe}_{4 / 2}\right]$ tetrahedra connected by edges and corners but presenting some homonuclear bonds like Ge-Ge in lower proportion and Se-Se in higher proportion than films performed at lower pressure.

Fig. $1 \mathrm{~b}$ presents Raman spectra of Se-6 sputtered thin films and chalcogenide target with the $\mathrm{Ge}_{12.5} \mathrm{Sb}_{25} \mathrm{Se}_{62.5}$ nominal composition. The major band corresponds to a large envelope made of several overlapping bands attributed to vibration modes of corner linked $\left[\mathrm{GeSe}_{4 / 2}\right]$ tetrahedra $\left(\sim 200 \mathrm{~cm}^{-1}\right)$ and $\left[\mathrm{GeSe}_{4 / 2}\right]$ tetrahedra connected by edges $\left(\sim 215 \mathrm{~cm}^{-1}\right)$ and contribution of stretching mode of Sb-Se of $\left[\mathrm{SbSe}_{3 / 2}\right]$ pyramids $\left(\sim 190 \mathrm{~cm}^{-1}\right)$. A contribution of Ge-Ge bonds of $\mathrm{Ge}_{2} \mathrm{Se}_{6 / 2}$ can also be noted at $\sim 175 \mathrm{~cm}^{-1}$ and $\mathrm{Sb}-(\mathrm{Ge}) \mathrm{Sb}$ bonds in $\mathrm{Se}_{2} \mathrm{Sb}(\mathrm{Ge})-\mathrm{SbSe}_{2}$ structural motifs $\left(\sim 160 \mathrm{~cm}^{-1}\right)$ for the lowest pressure and not observed in case of the highest pressure. The presence of $\mathrm{Se}_{2} \mathrm{Sb}(\mathrm{Ge})-\mathrm{SbSe}_{2}$ entities is clearly shown in case of Se-6 films with low Ar pressure of about $5.10^{-3}$ mbar which is related to the deficit of selenium and the higher proportion of antimony compared to Se-2 sputtered films composition. As shown in Fig. $2 b$, intensity ratio of $\mathrm{Ge}(\mathrm{Sb})-\mathrm{Ge}(\mathrm{Sb})$ bonds $\left(\sim 160-175 \mathrm{~cm}^{-1}\right)$ compared to corner-shared and edge-shared entities $\left(\sim 200\right.$ and $\left.\sim 215 \mathrm{~cm}^{-1}\right)$ decreases for higher Ar pressure. Thus like in the case of Se-2 sputtered thin films, it is for higher Ar pressures $\left(1.10^{-2}\right.$ and $\left.5.10^{-2} \mathrm{mbar}\right)$ that rich-Sb thin films $\left(\mathrm{Ge}_{12.5} \mathrm{Sb}_{25} \mathrm{Se}_{62.5}\right)$ are closer to target structure. Likewise, EDS analysis (Table 1) confirms that at high Ar pressure (5.10-2 mbar), chemical composition of RF sputtered thin films is close to target composition.

In addition to Raman spectroscopy, X-ray photoelectron spectroscopy is used to describe bonding arrangement at the surface of Ge-Sb-Se RF sputtered thin films. Therefore, structure of $\mathrm{Ge}_{28.1} \mathrm{Sb}_{6.3} \mathrm{Se}_{65.6}$ ) (Fig. 3, Table 2) and $\mathrm{Ge}_{12.5} \mathrm{Sb}_{25} \mathrm{Se}_{62.5}$ (Fig. 4, Table 3) thin films, deposited under various Ar pressures $\left(5.10^{-3}, 7.5 .10^{-3}, 1.10^{-2}\right.$ and $5.10^{-2}$ mbar), were studied by XPS and surface chemical composition was also compared to EDS analysis (Fig. 5).

For both thin films $\mathrm{Ge}_{28.1} \mathrm{Sb}_{6.3} \mathrm{Se}_{65.6}$ and $\mathrm{Ge}_{12.5} \mathrm{Sb}_{25} \mathrm{Se}_{62.5}$, the agreement between chemical composition estimated by XPS and EDS is fine as shown in Fig. 5. Indeed the two compositions of thin films compared to target follow the same general behavior for the three elements. A deficiency in chalcogen element is 
observed for lower pressure $\left(\leq 1.10^{-2}\right.$ mbar) while high Ar pressure $\left(5.10^{-2}\right.$ mbar $)$ show an excess of Se. In most cases, sputtering deposition from a complex compound target results in a loss of the more volatile elements (e.g. selenium in case of Ge-Sb-Se targets) especially for low Ar pressure [43]. On the other hand, thin films are in excess of germanium at low Ar pressure $\left(\leq 1.10^{-2} \mathrm{mbar}\right)$, , and in slight deficit for the higher pressure $\left(5.10^{-2} \mathrm{mbar}\right)$ which can be related to sputtering rate and mean free path of particles changes. Finally, antimony content of Se-2 thin films is close to target composition whatever the pressure, a similar situation is also observed for Se-6 thin films at least from EDS results and for higher Ar pressure $\left(1.10^{-2}\right.$ and $5.10^{-2}$ mbar $)$ for XPS analysis.

For a given pressure, different sputtering yields for each atom of a complex target will lead to a change in the initial composition of the target. This change is counterbalance by the fact that the concentration of elements preferably sputtered on the surface will decrease to achieve a so-called equilibrium composition at the surface of the target. It will allow obtaining films of substantially similar composition to that of the starting targets. However, in many cases, some of the lightest and most volatile species, such as chalcogens, are lost in the transfer between the target and the substrate or the probability of reaction with the more condensable species on the substrate surface is less effective. The equilibrium composition can also drift from stoichiometric one if sputtering yields are quite different from each other. These behaviors can lead to a loss of stoichiometry in the deposited film from the target material. The sputtering yield for elements conventionally present in the chalcogenide layers has been reported in the literature with a high yield for chalcogens (selenium and then tellurium, and finally sulfur) [44]. Antimony also possesses a good sputtering yield, however twice less than that of selenium and finally germanium sputtering yield is the less efficient, a third of the selenium one.

Energy distribution of the sputtered atoms leaving the target can be expressed using the model developed by Thompson [45]. Such distribution mainly depends on the global characteristics of the sputtered material (reduced mass and cohesive energy) and sputtering ion energy. In the present case sputtering is carried out at low power, which results in a very shallow sheath $(\sim 1-3 \mathrm{~mm})$ in front of the target. Therefore sputtering $\mathrm{Ar}^{+}$ions are expected not to suffer from 
any collision processes, when accelerated through the sheath; and in all our various pressure condition all sputtered atoms are assumed to have a similar energy distribution as they leave the target. Energy distribution of the sputtered atoms at the substrate level may be deeply modified, according to the average number of collision with the atoms of the gas they encounter during their transport. Using the work of Gras-Marti [46] and Meyer [47], and assuming a gas temperature of $500 \mathrm{~K}$, we can estimate that the average atom energy is typically $2-4 \mathrm{eV}$, both at the target position and at the substrate position, for pressure conditions of $510^{-3}$ up to $110^{-2}$ mbar. Opposite a much lower value of $0.1 \mathrm{eV}$ is estimated for the $510^{-2}$ mbar condition. Another point to consider that could modify the flux of atoms is nucleation process during transport. However the Ar pressure is low enough that nucleation is not so important; i.e. pressure greater than $\sim 7.10^{-3}$ mbar but less than about $\sim 7.10^{-2}$ mbar [48]. Thus, the concentration of films deposited at lower pressure are mainly following the sputtering yields of the Se, Sb and Ge and the particles with long mean free path are not so much perturbed by collision during the transfer from target to substrate. It is not the case of deposition at higher pressure $\left(>7.5 .10^{-3}\right.$ mbar) where the sputtered particles are more affected by multiple collisions and thermalization of the particles which will modify the composition, structure and morphology of the thin films.

Considering XPS analysis, the structure of Sb 4d - Ge 3d core-level bands are relatively complex to describe because of the overlap between the various contributions. It can be noticed that $\mathrm{Sb} 4 \mathrm{~d}$ and Ge $3 \mathrm{~d}$ core levels spectra reflect the variation of Ge/Sb ratio analyzed by EDS regarding to Ar pressure. So, for these both compositions $\mathrm{Ge}_{28.1} \mathrm{Sb}_{6.3} \mathrm{Se}_{65.6}(\mathrm{Se}-2)$ and $\mathrm{Ge}_{12.5} \mathrm{Sb}_{25} \mathrm{Se}_{62.5}(\mathrm{Se}-6)$, the presence of [SbSe ${ }_{3}$ ] and [GeSe ${ }_{4}$ ] entities can be mainly observed. Nevertheless, low contents of $(\mathrm{Ge}, \mathrm{Sb})-\mathrm{Sb}-\mathrm{Se}_{2}$ and $(\mathrm{Ge}, \mathrm{Sb})-\mathrm{Ge}-\mathrm{Se}_{3}$ have to be considered (Fig. 3 and Fig. 4); these $\mathrm{M}-\mathrm{M}$ (M = Ge, Sb) bonds were also demonstrated for based-Se glasses [29, 49], for $\mathrm{Ge}_{\mathrm{x}} \mathrm{Sb}_{10} \mathrm{Se}_{90-\mathrm{x}}$ glasses (with x from 7.5 to 32.5 at. \%), and for $\left(\mathrm{GeSe}_{2}\right)_{100-\mathrm{x}}\left(\mathrm{Sb}_{2} \mathrm{Se}_{3}\right)_{\mathrm{x}}$ glasses [26]. The proportion of $\left(\mathrm{Ge}_{\mathrm{O}} \mathrm{Sb}_{\text {- }}\right.$ $\mathrm{Sb}_{-} \mathrm{Se}_{2}$ bonds is about $17 \%$ and $9 \%$ (for Se-2 thin films) and $23 \%$ and $0 \%$ (for Se-6 thin films) for the $5.10^{-3}$ and $5.10^{-2}$ mbar sputtering conditions. In the same way, the proportion of (Ge,Sb)-Ge-Se ${ }_{3}$ bonds is about $22 \%$ and $5 \%$ (for $\mathrm{Ge}_{28.1} \mathrm{Sb}_{6.3} \mathrm{Se}_{65.6}$ ) and $47 \%$ and $0 \%\left(\right.$ for $\mathrm{Ge}_{12.5} \mathrm{Sb}_{25} \mathrm{Se}_{62.5}$ ) for the $5.10^{-3}$ and 5.10 
${ }^{2}$ mbar sputtering conditions. These results are in agreement with Raman analysis, which shows a decreasing proportion of bands attributed to Ge-Ge bonds $\left(\sim 175 \mathrm{~cm}^{-1}\right)$ and $\mathrm{Sb}-(\mathrm{Ge}) \mathrm{Sb}$ bonds $\left(\sim 160 \mathrm{~cm}^{-1}\right)$ as the Ar pressure is increased (Fig. 2$)$.

In the case of Se, two doublets $\left(3 \mathrm{~d}_{5 / 2}\right.$ and $\left.3 \mathrm{~d}_{3 / 2}\right)$ are necessary to analyze Se $3 \mathrm{~d}$ curve (Fig. $3 \mathrm{i}-1$ and Fig. $\left.4 \mathrm{i}-1\right)$, with an exception for the Ge ${ }_{12.5} \mathrm{Sb}_{25} \mathrm{Se} 62.5$ film at $5.10^{-3}$ mbar condition. Due to comparable electronegativities of Ge (2.01) and $\mathrm{Sb}(2.05)$ [29, 49], the main entities (Ge,Sb)-Se-(Ge,Sb) present in thin films network are expected to be located at similar chemical shifts. These moieties are responsible for the main contribution located at $\sim 53.50 \pm 0.05 \mathrm{eV}$ for Se- 6 and $\sim 53.75 \pm 0.05 \mathrm{eV}$ for Se-2. The second component is located at $54.3 \pm 0.1 \mathrm{eV}$. Considering Se-O $\mathrm{x}_{\mathrm{x}}$ entities we can waive such attribution, as the position of Se$\mathrm{O}_{\mathrm{x}}$ has already been established in these films at $55.3 \mathrm{eV}$ from the curve fitting of Se $3 \mathrm{~d}\left(3 \mathrm{~d}_{5 / 2}\right.$ and $\left.3 \mathrm{~d}_{3 / 2}\right)$ for an angle of $70^{\circ}[20]$. On another hand, such second component is frequently attributed to an entity with homonuclear bonds Se-Se-(Ge,Sb) [15, 29, 49]. Considering this interpretation, we observe that the content of Se-Se-(Ge,Sb) bonds is higher for thin films deposited under high Ar pressure (Fig. $3 \mathrm{i}$ to 1 and Fig. $4 \mathrm{i}$ to 1$)$. The content vary from 0 to $22 \%$ and from 15 to $32 \%$ when increasing the Ar pressure, respectively for Se-6 and Se-2 sputtered films in agreement with previous XPS results obtained for sputtered thin films with target composition of $\mathrm{Ge}_{28} \mathrm{Sb}_{12} \mathrm{Se}_{60}[20]$. This trend is quite coherent with the Raman spectroscopy analysis, as for highest Ar pressure (5.10-2 mbar), a band clearly increases at $\sim 265 \mathrm{~cm}^{-1}$ often related to the vibration of Se-Se bond linking two [GeSe $\left.\mathrm{G}_{4 / 2}\right]$ tetrahedra by dimers or small $\mathrm{Se} \mathrm{n}_{\mathrm{n}}$ chains. If the presence of Se-Se homonuclear bonds are revealed by Raman analyses even for lower Ar pressure, the proportion of homonuclear bonds Se-Se-(Ge,Sb) in Se2 and Se-6 thin films is not expected to be so high in these composition close to stoichiometric composition or with a deficit in Se. Therefore, another contribution to this second Se $3 \mathrm{~d}$ core level component spectrum might be considered: Se involved in bonds between two [GeSe $4 / 2$ ] tetrahedra connected by edges could also contribute to Se-Se-(Ge,Sb) component [20, 49] (Fig. 2). 
As regards Ge 3d core-level (Fig. 3a to d and Fig. 4a to d), the relative proportion related to [GeSe ${ }_{4 / 2}$ ] tetrahedra increases following Ar pressure rise (Table 2 and Table 3), from 78 to $95 \%$ and from 53 to $100 \%$ from $5.10^{-3}$ to $5.10^{-2}$ mbar, respectively for Se-2 and Se-6 thin films. A similar evolution is observed for the $\left[\mathrm{SbSe}_{3 / 2}\right]$ entity, which increases from 83 to $89 \%$ and from 77 to $100 \%$ from $5.10^{-3}$ to $5.10^{-2}$ mbar, respectively for Se-2 and Se-6 thin films. Thus, at high Ar pressure, the M-M bonds $(\mathrm{M}=\mathrm{Ge}, \mathrm{Sb})$ decrease substantially confirming Raman spectroscopy study. Analysis of the Sb3d - O1s spectral region does not bring additional information about the Sb chemical environment. However, it puts forward the very low amount of oxygen at the sample surface. To conclude, XPS and Raman results lead us to conclude that it is possible to adjust Ar pressure in order to obtain different structural properties using one chalcogenide target. .

Ionic erosion with $\mathrm{Ar}^{+}$ions $(4 \mathrm{kV}, 100 \mu \mathrm{A})$ of Se-6 sputtered thin films surface was also performed allowing to evaluate the usefulness of ionic erosion in case of oxidized chalcogenide films. Thin films deposited under Ar pressure $5.10^{-3}$ and $5.10^{-2}$ mbar were eroded for 120 seconds followed by XPS analysis; a second erosion of 720 seconds with XPS analysis was then performed. Results are presented in Fig. 6. These films exhibit significant surface oxidation before erosion, as this experiment was carried out several weeks after the XPS characterization reported above. After 120 seconds of erosion, disappearance of oxides ( $\mathrm{Sb} 3 \mathrm{~d}$ and Ge $2 \mathrm{p}$ core levels) can be noted. Moreover, a filling between the two Sb $4 \mathrm{~d}$ core levels is observed, that means there is an additional doublet Sb4d shifted towards lowest energies. Likewise, Ge $3 \mathrm{~d}$ core level, after 120 seconds of erosion, shows a strong broadening in low energy side. After 720 seconds of erosion, this broadening lightly increase; a rise of Ge-Ge and Sb-Sb bonds proportion can be observe as soon as thin film surface is eroded. The spectral shapes of the sputtered thin films $\left(5.10^{-3}\right.$ and $5.10^{-2}$ mbar) after erosion are similar. However we have observed a significant change of composition after erosion: the $\mathrm{Se} /(\mathrm{Ge}+\mathrm{Sb})$ ratio dropping to 1.3 and 1.2 after $120 \mathrm{~s}$ and $720 \mathrm{~s}$ respectively $(\sim 1.7$ for the fresh samples $)$, suggesting preferential sputtering of the lighter elements. This method of ionic erosion is sometimes used for the study of contaminated surface materials, as it allows to remove the first surface layers, or to achieve some depth profiling. Here it is obviously demonstrated that it is not appropriated for selenide thin films analysis due to higher sputtering rate of 
selenium compare to other elements. Nevertheless, this ionic erosion technique enables to determine and confirm the position of $\mathrm{M}-\mathrm{M}$ bonds $(\mathrm{M}=\mathrm{Ge}$, $\mathrm{Sb}$ ) precisely.

The oxidation effect on selenide sputtered thin films has been revealed with the take-off angle variation between two films deposited under $5.10^{-2} \mathrm{mbar}$ and $5.10^{-3}$ mbar of Ar pressure where the morphology plays a major role during films aging [20]. Such analysis is used here to study the extreme surface of fresh selenide thin films with two different compositions, i.e. the first $2-3 \mathrm{~nm}\left(\right.$ at $\left.70^{\circ}\right)$ compared to a deeper analysis (at $0^{\circ}$ ), i.e. the first top $\sim 10 \mathrm{~nm}$. Fig. 7 shows the 0,60 and $70^{\circ}$ take-off angles for $\mathrm{Ge}_{28.1} \mathrm{Sb}_{6.3} \mathrm{Se}_{65.6}(\mathrm{Se}-2)$ and $\mathrm{Ge}_{12.5} \mathrm{Sb}_{25} \mathrm{Se}_{62.5}(\mathrm{Se}-6)$ thin films for $5.10^{-2} \mathrm{Ar}$ pressure. The different spectra at $0^{\circ}, 60^{\circ}$ and $70^{\circ}$ are similar; in particular the Sb4d-Ge3d and the Sb3d - O1s core level band shows no evidence for Sb-oxide or Ge-oxide, and no evidence of an increase in the relative amount of oxygen. Thus in case of fresh films, the two compositions Se-2 and Se-6 present very weak residual oxide pollution of the thin films, and the proportion of $\mathrm{Se}-\mathrm{O}_{\mathrm{x}}$ is also expected to be very low.

\section{Conclusions}

In this paper, X-rays photoelectron and Raman spectroscopies were used to study the influence of Ar pressure on the structure of sputtered thin films with the nominal composition $\mathrm{Ge}_{28.1} \mathrm{Sb}_{6.3} \mathrm{Se}_{65.6}$ and $\mathrm{Ge}_{12.5} \mathrm{Sb}_{25} \mathrm{Se}_{62.5}$. The difference in chemical composition between glass target and thin films deposited under different Ar pressure was also investigated by XPS and EDS analysis. The sputtered film composition has been related to the Ar pressure and the transport of the sputtered particles: deposited at lower Ar pressure (i.e., $<7.5 .10^{-3} \mathrm{mbar}$ ), the composition is predominantly constrained by the sputtering yields of the Se, $\mathrm{Sb}$ and Ge. The particles are almost not bothered by collision during the transfer from target to substrate while at higher pressure (i.e., $>7.5 .10^{-3} \mathrm{mbar}$ ), the sputtered particles are more affected by multiple collisions and particles thermalization which will modify the composition, structure and morphology of the thin films. XPS and Raman analysis demonstrates that thin film network is closer to the target structure for high Ar pressure (5.10 ${ }^{-2}$ mbar), i.e. mainly 
composed of $\left[\mathrm{GeSe}_{4 / 2}\right]$ tetrahedra connected by edges and corners for $\mathrm{Ge}_{28.1} \mathrm{Sb}_{6.3} \mathrm{Se}_{65.6}$ thin films and [ $\left.\mathrm{SbSe}_{3 / 2}\right]$ pyramids for $\mathrm{Ge}_{12.5} \mathrm{Sb}_{25} \mathrm{Se}_{62.5}$ thin films. A low

Ar pressure leads to the formation of Ge-Ge in $\left[\mathrm{Ge}_{2} \mathrm{Se}_{6 / 2}\right]$ entities for $\mathrm{Ge}_{28.1} \mathrm{Sb}_{6.3} \mathrm{Se}_{65.6}$ and $\mathrm{Sb}(\mathrm{Ge})-\mathrm{Sb}$ entities for $\mathrm{Ge}_{12.5} \mathrm{Sb}_{25} \mathrm{Se}_{62.5}$ films with a clear deficit in Se in comparison with the stoichiometric composition of the target.

\section{Acknowledgments}

The authors thank the Région Bretagne, the IFREMER and the BRGM for the thesis fund. They also thank the SIR platform of ScanMAT at

University of Rennes 1 for their technical assistance for Raman spectroscopy.

\section{References}

[1] K. Michel, B. Bureau, C. Boussard-Pledel, T. Jouan, J.L. Adam, K. Staubmann, T. Baumann, Monitoring of pollutant in waste water by infrared spectroscopy using chalcogenide glass optical fibers, Sensors and Actuators B-Chemical, 101 (2004) 252-259.

[2] D. Le Coq, K. Michel, J. Keirsse, C. Boussard-Pledel, G. Fonteneaua, B. Bureau, J.M. Le Quere, O. Sire, J. Lucas, Infrared glass fibers for in-situ sensing, chemical and biochemical reactions, C. R. Chim., 5 (2002) 907-913.

[3] F. Charpentier, J. Troles, Q. Coulombier, L. Brilland, P. Houizot, F. Smektala, C. Boussard-Pledel, V. Nazabal, N. Thibaud, K. Le Pierres, Renversez, B. Bureau, CO2 Detection Using Microstructured Chalcogenide Fibers, Sens. Lett., 7 (2009) 745-749.

[4] J. Keirsse, C. Boussard-Pledel, O. Loreal, O. Sire, B. Bureau, P. Leroyer, B. Turlin, J. Lucas, IR optical fiber sensor for biomedical applications, Vib. Spectrosc., 32 (2003) 23-32.

[5] C. Vigreux-Bercovici, V. Ranieri, L. Labadie, J.E. Broquin, P. Kern, A. Pradel, Waveguides based on Te2As3Se5 thick films for spatial interferometry, J. Non-Cryst. Solids, 352 (2006) 2416-2419.

[6] M. Frumar, B. Frumarova, P. Nemec, T. Wagner, J. Jedelsky, M. Hrdlicka, Thin chalcogenide films prepared by pulsed laser deposition - new amorphous materials applicable in optoelectronics and chemical sensors, J. Non-Cryst. Solids, 352 (2006) 544-561.

[7] V. Nazabal, M. Cathelinaud, W. Shen, P. Nemec, F. Charpentier, H. Lhermite, M.L. Anne, J. Capoulade, F. Grasset, A. Moreac, S. Inoue, M. Frumar, J.L. Adam, M. Lequime, C. Amra, Chalcogenide coatings of Ge15Sb20S65 and Te20As30Se50, Appl. Optics, 47 (2008) C114-C123. 
[8] B. Bureau, X.H. Zhang, F. Smektala, J.L. Adam, J. Troles, H.L. Ma, C. Boussard-Pledel, J. Lucas, P. Lucas, D. Le Coq, M.R. Riley, J.H. Simmons, Recent advances in chalcogenide glasses, J. Non-Cryst. Solids, 345 (2004) 276-283.

[9] F. Verger, T. Pain, V. Nazabal, C. Boussard-Pledel, B. Bureau, F. Colas, E. Rinnert, K. Boukerma, C. Compere, S. Ollivier, M. Guilloux-Viry, S. Deputier, A. Perrin, J.P. Guin, Surface enhanced infrared absorption (SEIRA) spectroscopy using gold nanoparticles on As2S3 glass, in: Eurosensors Xxv, 2011. [10] P. Nemec, V. Nazabal, M. Frumar, Photoinduced phenomena in amorphous As4Se3 pulsed laser deposited thin films studied by spectroscopic ellipsometry, Journal of Applied Physics, 106 (2009).

[11] E. Nicoletti, D. Bulla, B. Luther-Davies, M. Gu, Generation of lambda/12 Nanowires in Chalcogenide Glasses, Nano Lett., 11 (2011) $4218-4221$.

[12] X. Gai, S. Madden, D.Y. Choi, D. Bulla, B. Luther-Davies, Dispersion engineered Ge11.5As24Se64.5 nanowires with a nonlinear parameter of 136W(1)m(-1) at 1550nm, Opt. Express, 18 (2010) 18866-18874.

[13] A. Prasad, C.J. Zha, R.P. Wang, A. Smith, S. Madden, B. Luther-Davies, Properties of GexAsySe1-x-y glasses for all-optical signal processing, Opt. Express, 16 (2008) 2804-2815.

[14] Z.U. Borisova, Glassy Semiconductors, in, Plenum Press, New-York and London, 1981.

[15] S. Chen, Wang, Wang, Dai, Xu, Nie, Optical and structural properties of Ge-Sb-Se thin films fabricated by sputtering and thermal evaporation, Journal of alloys and compounds, (2012).

[16] W. Zhang, Y. Chen, J. Fu, F.F. Chen, X. Shen, S.X. Dai, C.G. Lin, T.F. Xu, Study on fabrication and optical properties of Ge-Sb-Se thin films, Acta Phys. Sin., 61 (2012) 6.

[17] R.M. Almeida, L.F. Santos, A. Simens, A. Ganjoo, H. Jain, Structural heterogeneity in chalcogenide glass films prepared by thermal evaporation, J. NonCryst. Solids, 353 (2007) 2066-2068.

[18] H.M. Hosni, S.A. Fayek, S.M. El-Sayed, M. Roushdy, M.A. Soliman, Optical properties and DC electrical conductivity of Ge28-xSe72Sbx thin films, Vacuum, 81 (2006) 54-58.

[19] V. Nazabal, Charpentier, F., Adam J-L., Sputtering and Pulsed Laser Deposition for Near- and Mid-Infrared Applications: A Comparative Study of Ge25Sb10S65 and Ge25Sb10Se65 Amorphous Thin Films, International Journal of Applied Ceramic Technology, 8 (2011) 990-1000.

[20] F. Verger, V. Nazabal, F. Colas, P. Nemec, C. Cardinaud, E. Baudet, R. Chahal, E. Rinnert, K. Boukerma, I. Peron, S. Deputier, M. Guilloux-Viry, J.P. Guin, H. Lhermite, A. Moreac, C. Compere, B. Bureau, RF sputtered amorphous chalcogenide thin films for surface enhanced infrared absorption spectroscopy, Optical Materials Express, 3 (2013) 2112-2131.

[21] J. Li, X. Shen, J.Q. Sun, K. Vu, D.Y. Choi, R.P. Wang, B. Luther-Davies, S.X. Dai, T.F. Xu, Q.H. Nie, Fabrication and characterization of Ge20Sb15Se65 chalcogenide glass rib waveguides for telecommunication wavelengths, Thin Solid Films, 545 (2013) 462-465.

[22] M. Olivier, P. Nemec, G. Boudebs, R. Boidin, C. Focsa, V. Nazabal, Photosensitivity of pulsed laser deposited Ge-Sb-Se thin films, Optical Materials Express, 5 (2015) 781-793.

[23] J. Charrier, M-L. Brandily, H. Lhermite, K. Michel, B. Bureau, F. Verger, V. Nazabal, Evanescent wave optical micro-sensor based on chalcogenide glass, Sensors and Actuators B-Chemical, 173 (2012) 468-476.

[24] M.A. Schmidt, D.Y. Lei, L. Wondraczek, V. Nazabal, S.A. Maier, Hybrid nanoparticle-microcavity-based plasmonic nanosensors with improved detection resolution and extended remote-sensing ability, Nat. Commun., 3 (2012) 8.

[25] A. Ganjoo, H. Jain, C. Yu, R. Song, J.V. Ryan, J. Irudayaraj, Y.J. Ding, C.G. Pantano, Planar chalcogenide glass waveguides for IR evanescent wave sensors, Journal of Non-Crystalline Solids, 352 (2006) 584-588. 
[26] M. Olivier, J.C. Tchahame, P. Nemec, M. Chauvet, V. Besse, C. Cassagne, G. Boudebs, G. Renversez, R. Boidin, E. Baudet, V. Nazabal, Structure, nonlinear properties, and photosensitivity of $(\mathrm{GeSe} 2)(100-\mathrm{x})(\mathrm{Sb} 2 \mathrm{Se} 3)(\mathrm{x})$ glasses, Opt. Mater. Express, 4 525-540.

[27] P. Němec, M. Olivier, E. Baudet, A. Kalendová, P. Benda, V. Nazabal, Optical properties of (GeSe2)100-x(Sb2Se3)x glasses in near- and middleinfrared spectral regions, Mater. Res. Bull., 51 (2014) 176-179.

[28] E. Baudet, M. Sergent, P. Němec, E. Rinnert, K. Michel, B. Bureau, V. Nazabal, Experimental design approach for deposition optimization of RF sputtered chalcogenide thin films devoted to environmental optical bio-chemical sensors, Sci Rep, (submitted).

[29] D.C. Sati, A. Kovalskiy, R. Golovchak, H. Jain, Structure of SbxGe40-xSe60 glasses around 2.67 average coordination number, Journal of NonCrystalline Solids, 358 (2012) 163-167.

[30] W.-H. Wei, S. Xiang, S.-W. Xu, L. Fang, R.-P. Wang, Structural investigation on GexSb10Se90-x glasses using x-ray photoelectron spectra, J. Appl. Phys., 115 (2014) 183506.

[31] Y. Chen, X. Shen, R.P. Wang, G.X. Wang, S.X. Dai, T.F. Xu, Q.H. Nie, Optical and structural properties of Ge-Sb-Se thin films fabricated by sputtering and thermal evaporation, J. Alloys Compd., 548 (2013) 155-160.

[32] L. Petit, N. Carlie, K. Richardson, Y. Guo, A. Schulte, B. Campbell, B. Ferreira, S.o.n. Martin, Effect of the substitution of S for Se on the structure of the glasses in the system Ge0.23Sb0.07S0.70-xSex, J. Phys. Chem. Solids, 66 (2005) 1788-1794.

[33] P. Nemec, B. Frumarová, M. Frumar, Structure and properties of the pure and Pr3+-doped Ge25Ga5Se70 and Ge30Ga5Se65 glasses, J. Non-Cryst. Solids, 270 (2000) 137-146.

[34] W.H. Wei, R.P. Wang, X. Shen, L. Fang, B. Luther-Davies, Correlation between Structural and Physical Properties in Ge-Sb-Se Glasses, J. Phys. Chem. C, 117 (2013) 16571-16576.

[35] S. Sugai, Stochastic random network model in Ge and Si chalcogenide glasses, Phys. Rev. B, 35 (1987) $1345-1361$.

[36] O. Matsuda, K. Inoue, K. Murase, Resonant Raman study on crystalline GeSe2 in relation to amorphous states, Solid State Communications, 75 (1990) 303-308.

[37] L. Petit, N. Carlie, R. Villeneuve, J. Massera, M. Couzi, A. Humeau, G. Boudebs, K. Richardson, Effect of the substitution of S for Se on the structure and non-linear optical properties of the glasses in the system Ge0.18Ga0.05Sb0.07S0.70-Se-x(x), Journal of Non-Crystalline Solids, 352 (2006) 5413-5420.

[38] K. Jackson, A. Briley, S. Grossman, D.V. Porezag, M.R. Pederson, C. system, Raman-active modes of a-GeSe2 and a-GeS2: A first-principles study, Physical Review B, 60 (1999) R14985-R14989.

[39] V. Nazabal, P. Nemec, A.M. Jurdyc, S. Zhang, F. Charpentier, H. Lhermite, J. Charrier, J.P. Guin, A. Moreac, M. Frumar, J.L. Adam, Optical waveguide based on amorphous Er3+-doped Ga-Ge-Sb-S(Se) pulsed laser deposited thin films, Thin Solid Films, $5184941-4947$.

[40] K. Murase, T. Fukunaga, K. Yakushiji, T. Yoshimi, I. Yunoki, Investigation of stability of (Ge, Sn)-(S, or Se)4/2 cluster by vibrational-spectra, Journal of Non-Crystalline Solids, 59-6 (1983) 883-886.

[41] J.E. Griffiths, G.P. Espinosa, J.C. Phillips, J.P. Remeika, RAMAN-SPECTRA AND ATHERMAL LASER ANNEALING OF GE(SXSE1-X)2

GLASSES, Physical Review B, 28 (1983) 4444-4453.

[42] T. Fukunaga, Y. Tanaka, K. Murase, Glass-formation and vibrational properties in the (Ge, Sn)Se system, Solid State Communications, 42 (1982) $513-$ 516.

[43] D.M. Mattox, Handbook of Physical Vapor Deposition (PVD) Processing, in: n. Edition (Ed.), Elsevier, 2010. 
[44] J. Orova, T. Tohoutek, T. Wagner, Deposition techniques for chalcogenides thin films, in: J.-L. Adam, X.-Z. Zhang (Eds.) Chalcogenide Glasses: Preparation, Properties and Applications, woodhead edition, 2014, pp. 265-344.

[45] M.W. Thompson, ENERGY SPECTRUM OF EJECTED ATOMS DURING HIGH ENERGY SPUTTERING OF GOLD, Philosophical Magazine, 18 (1968) 377-\&.

[46] A. Grasmarti, J.A. Vallesabarca, SLOWING DOWN AND THERMALIZATION OF SPUTTERED PARTICLE FLUXES - ENERGY-

DISTRIBUTIONS, Journal of Applied Physics, 54 (1983) 1071-1075.

[47] K. Meyer, I.K. Schuller, C.M. Falco, THERMALIZATION OF SPUTTERED ATOMS, Journal of Applied Physics, 52 (1981) 5803-5805.

[48] D.M. Mattox, Chapter 7 - Physical Sputtering and Sputter Deposition (Sputtering), in: Handbook of Physical Vapor Deposition (PVD) Processing (Second Edition), William Andrew Publishing, Boston, 2010, pp. 237-286.

[49] R. Golovchak, O. Shpotyuk, M. Iovu, A. Kovalskiy, H. Jain, Topology and chemical order in AsxGexSe1-2x glasses: A high-resolution X-ray photoelectron spectroscopy study, Journal of Non-Crystalline Solids, 357 (2011) 3454-3460.

Figures Captions

Fig. 1. Raman scattering spectra of sputtered thin films and targets with nominal composition Ge28.1Sb6.3Se65.6 (Se-2) (a) and Ge12.5Sb25Se62.5 (Se-6) (b)

Fig. 2. Intensity ratios for various Raman active vibration modes for Ge28.1Sb6.3Se62.5 (Se-2) (a) and Ge12.5Sb25Se62.5 (Se-6) (b) thin films. IES and ICS are intensities of A1c and A1 bands, respectively at $\sim 215$ and $\sim 200 \mathrm{~cm}-1$ (ES is for edge-shared and CS is for corner-shared tetrahedra). IM-M corresponds to homopolar bonds $\mathrm{Ge}-\mathrm{Ge}(\sim 170 \mathrm{~cm}-1)$

Fig. 3. Chemical compositions of Ge28.1Sb6.3Se65.6 ( $\mathrm{Se}-2)$ and Ge12.5Sb25Se62.5 (Se-6) sputtered thin films under different Ar pressure and glass targets $\mathrm{Se}-2$ and Se-6 determined by XPS and EDS analysis (lines are drawn as guides to the eyes).

Fig. 4. XPS data of Ge28.1Sb6.3Se65.6 (Se-2) sputtered films under 5.10-3, 7.5.10-3, 1.10-2 and 5.10-2 mbar of Ar: a) to d) curve fitting of Ge 3d and Sb 4d core-level spectra, e) to h) curve fitting of Sb $3 \mathrm{~d}$ core-level spectra and i) to 1) curve fitting of Se $3 \mathrm{~d}$ core-level spectra

Fig. 5. XPS data of Ge12.5Sb25Se62.5 (Se-6) sputtered films under 5.10-3, 7.5.10-3, 1.10-2 and 5.10-2 mbar of Ar: a) to d) curve fitting of Ge 3d and Sb 4d core-level spectra, e) to h) curve fitting of Sb $3 \mathrm{~d}$ core-level spectra and i) to 1) curve fitting of Se 3d core-level spectra

Fig. 6. XPS datas of Ge12.5Sb25Se62.5 (Se-6) sputtered films ( $\mathrm{Sb} 4 \mathrm{~d}$, Ge 3d) deposited under Ar pressure a) 5.10-3, b) 5.10-2 mbar depending of erosion time 0,120 and $720 \mathrm{~s}$ (dash-fitted components correspond to homopolar bonds and solid-fitted components correspond to heteropolar bonds for erosion time of 720 s) 
Fig. 7. XPS data of Ge28.1Sb6.3Se65.6 (Se-2) and Ge12.5Sb25Se62.5 (Se-6) sputtered films under 5.10-2 mbar of Ar, Se 3d core level spectra a) and d), Ge $3 \mathrm{~d}-\mathrm{Sb} 4 \mathrm{~d}$ core level spectra $\mathrm{b}$ ) and e) and $\mathrm{Sb} 3 \mathrm{~d}-\mathrm{O} 1 \mathrm{~s}$ core level spectra c) and f) for $0^{\circ}, 60^{\circ}$ and $70^{\circ}$ take-off angles

\section{Tables captions}

\section{Table 1}

Theoretical and real chemical composition determined by EDS ( $\pm 0.5 \%)$ of chalcogenide glass targets and $( \pm 1 \%)$ sputtered thin films Se-2 and Se- 6

\section{Table 2}

Binding energy (BE, $\pm 0.05 \mathrm{eV}$ ), full width at half maximum (FWHM, $\pm 0.05 \mathrm{eV}$ ) and proportion of bonds (\%) of the different components used for the fitting of Se $3 \mathrm{~d}_{5 / 2}$, Ge $3 \mathrm{~d}_{5 / 2}$ and $\mathrm{Sb} 4 \mathrm{~d}_{5 / 2}$ core-level spectra for $\mathrm{Ge}_{28.1} \mathrm{Sb}_{6.3} \mathrm{Se}_{65.6}(\mathrm{Se}-2)$ sputtered films under 5.10 $0^{-3}, 7.5 .10^{-3}, 1.10^{-2}$ and $5.10^{-2} \mathrm{mbar}$ of Ar

\section{Table 3}

Binding energy (BE, $\pm 0.05 \mathrm{eV}$ ), full width at half maximum (FWHM, $\pm 0.05 \mathrm{eV}$ ) and proportion of bonds (\%) of the different components used for the fitting

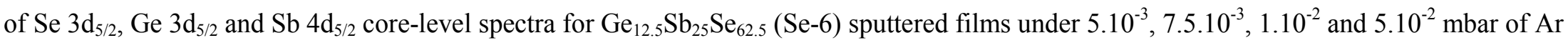



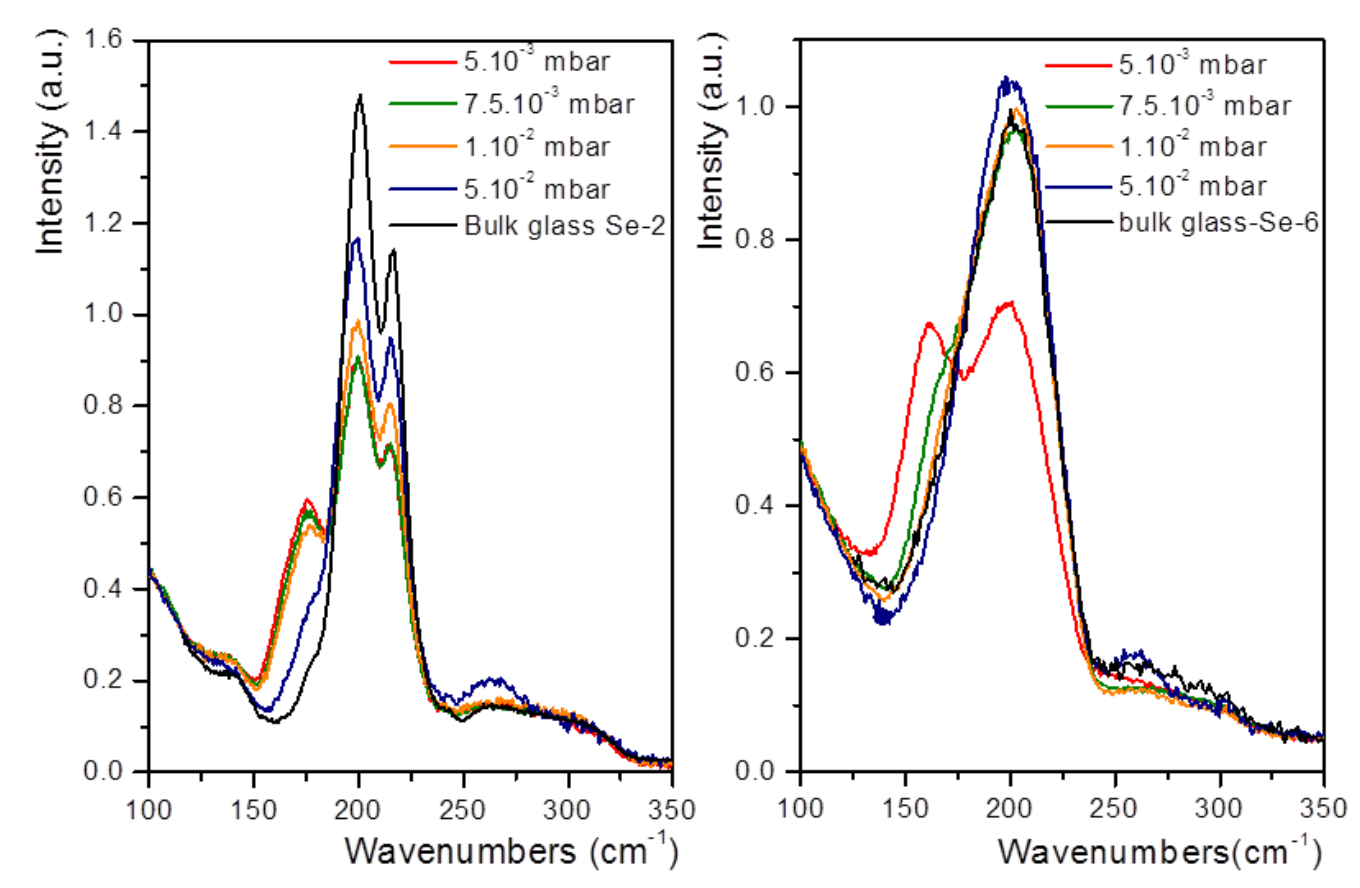

Figure 1 

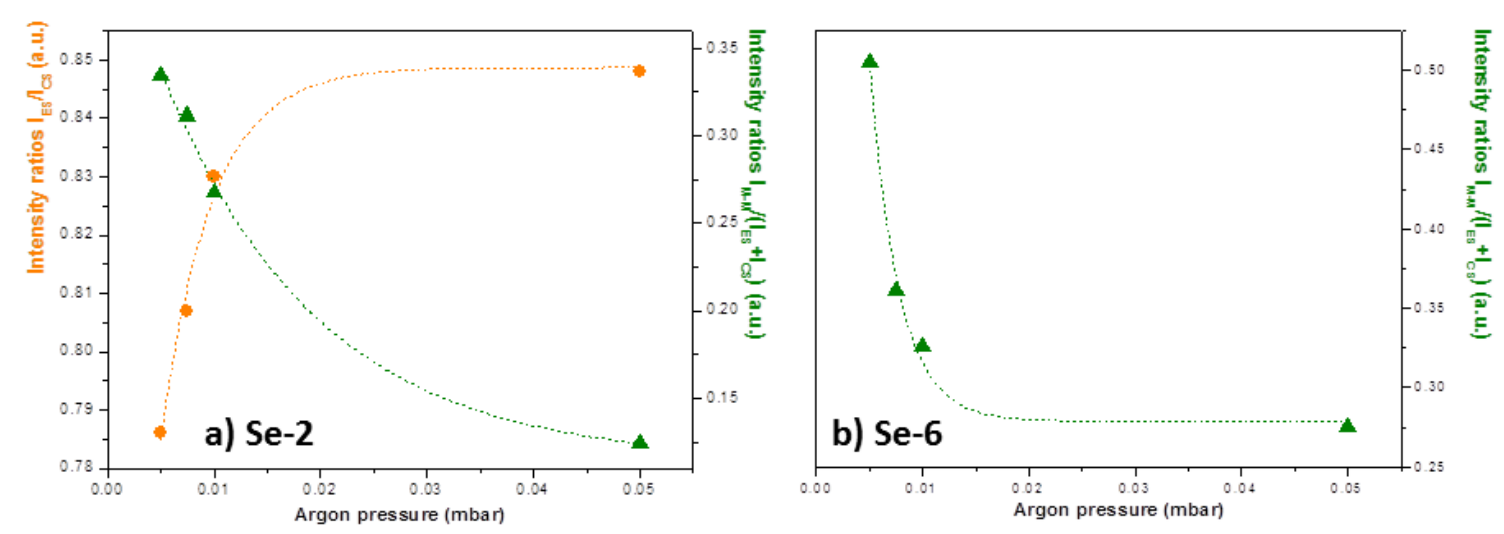

Figure 2 

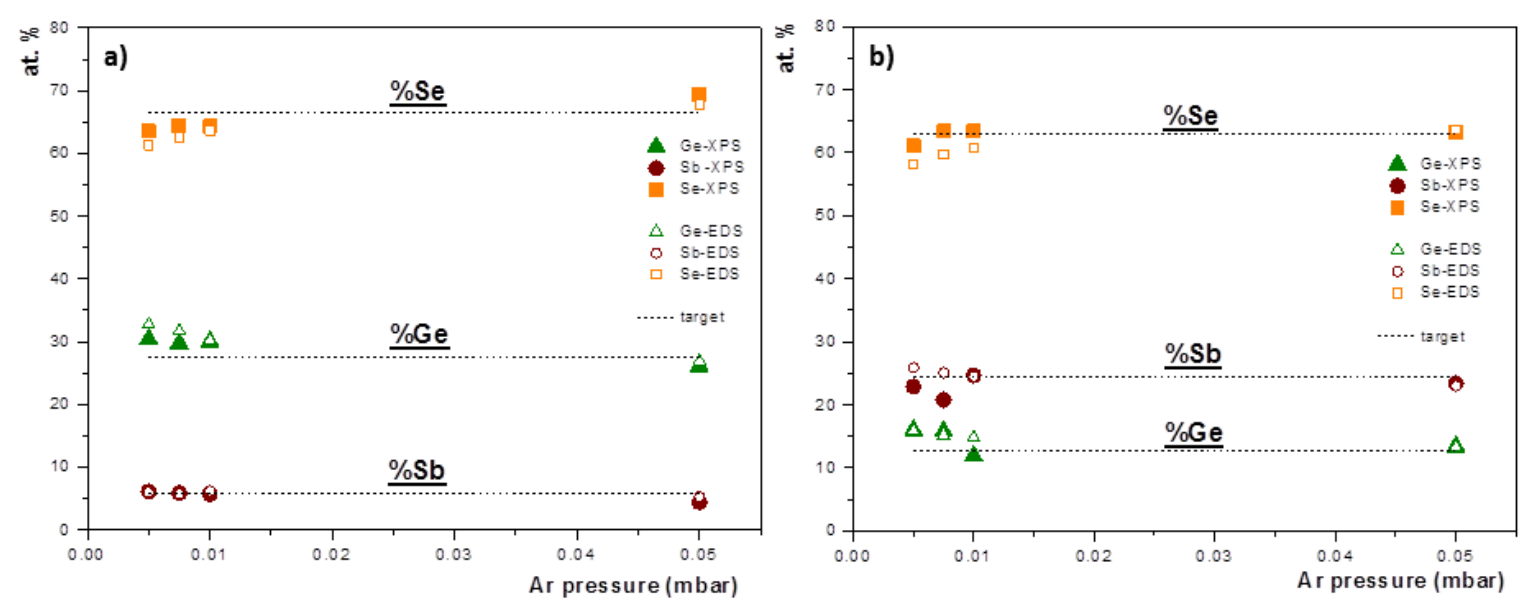

Figure 3 

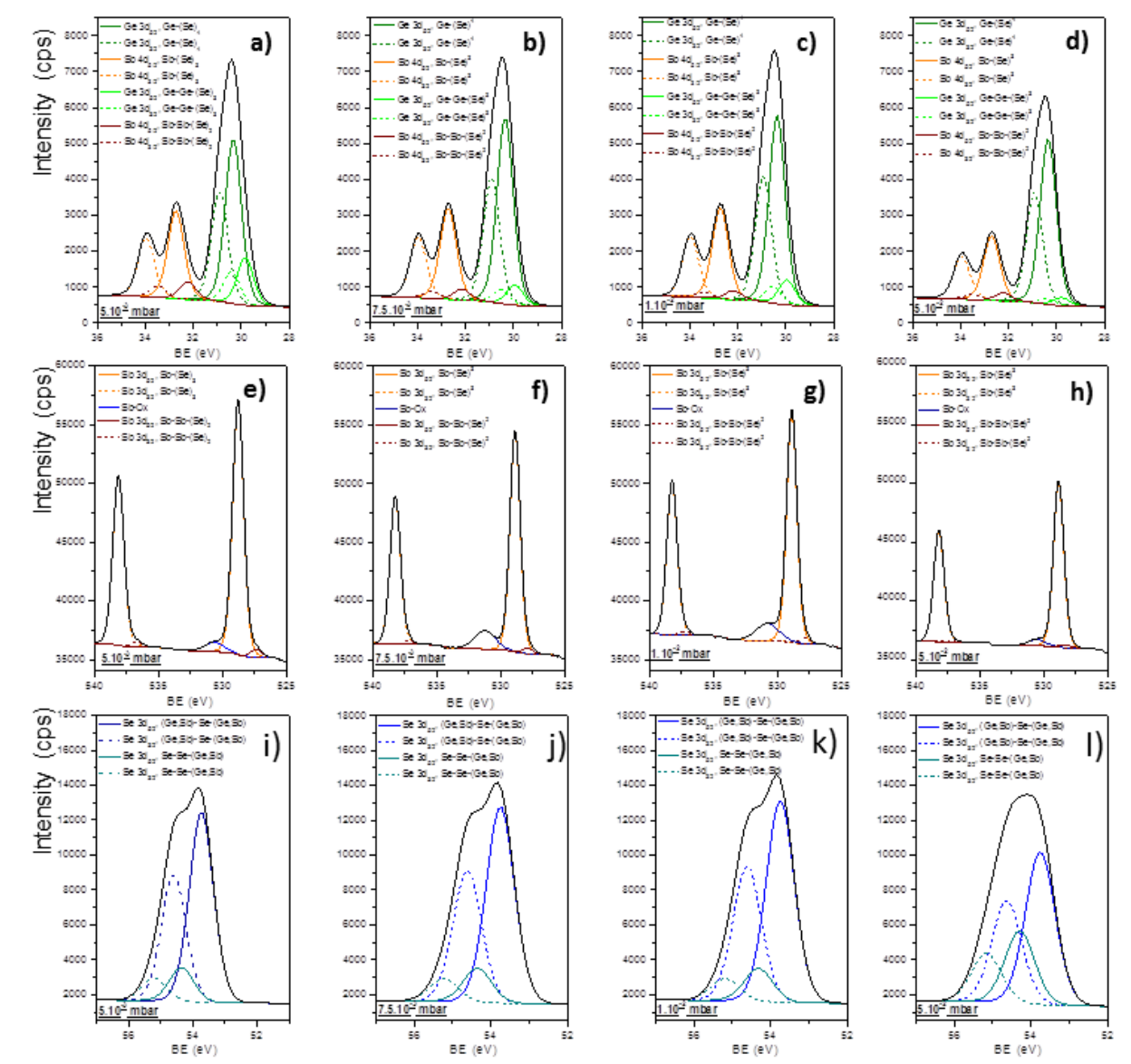

Figure 4 

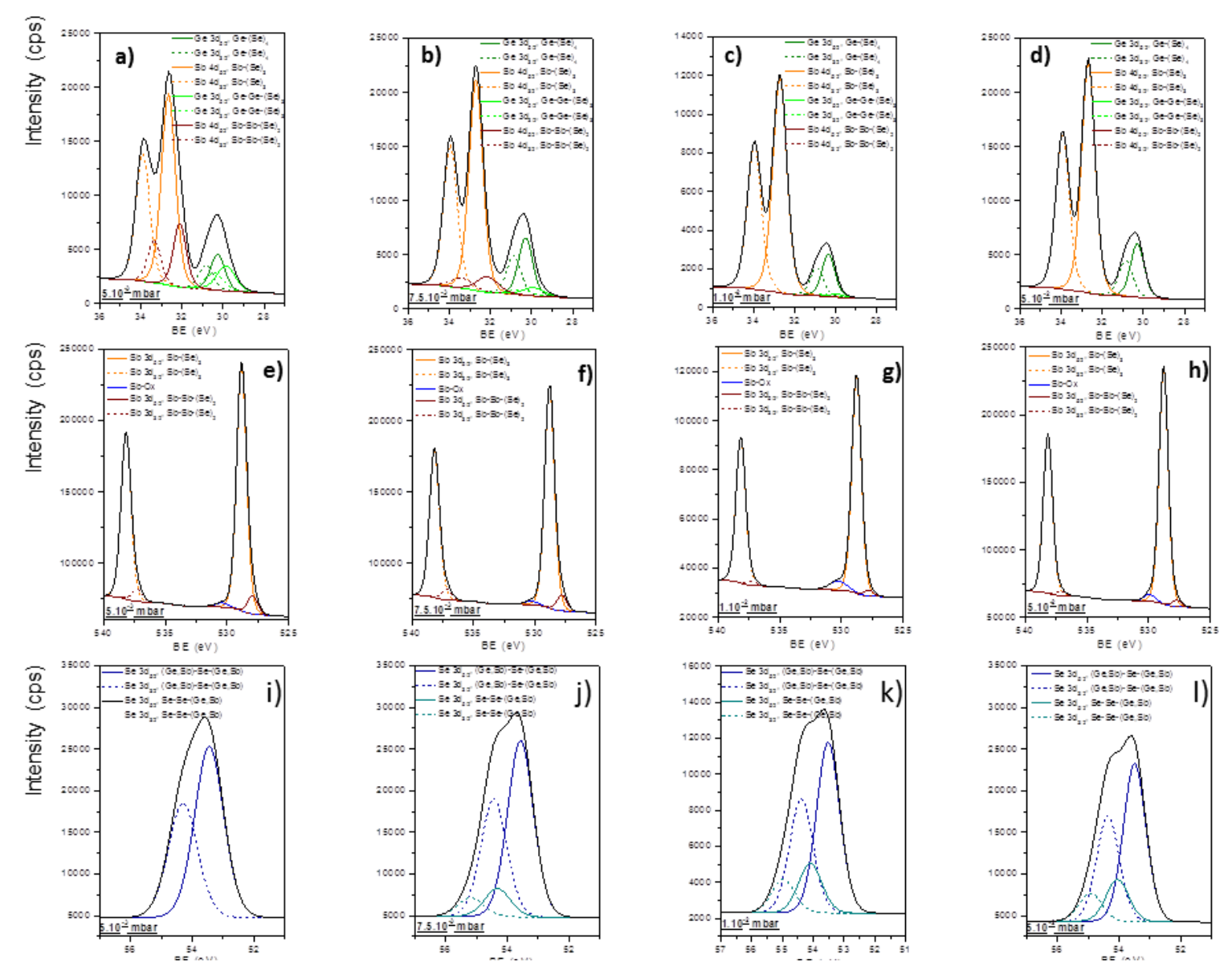

Figure 5 

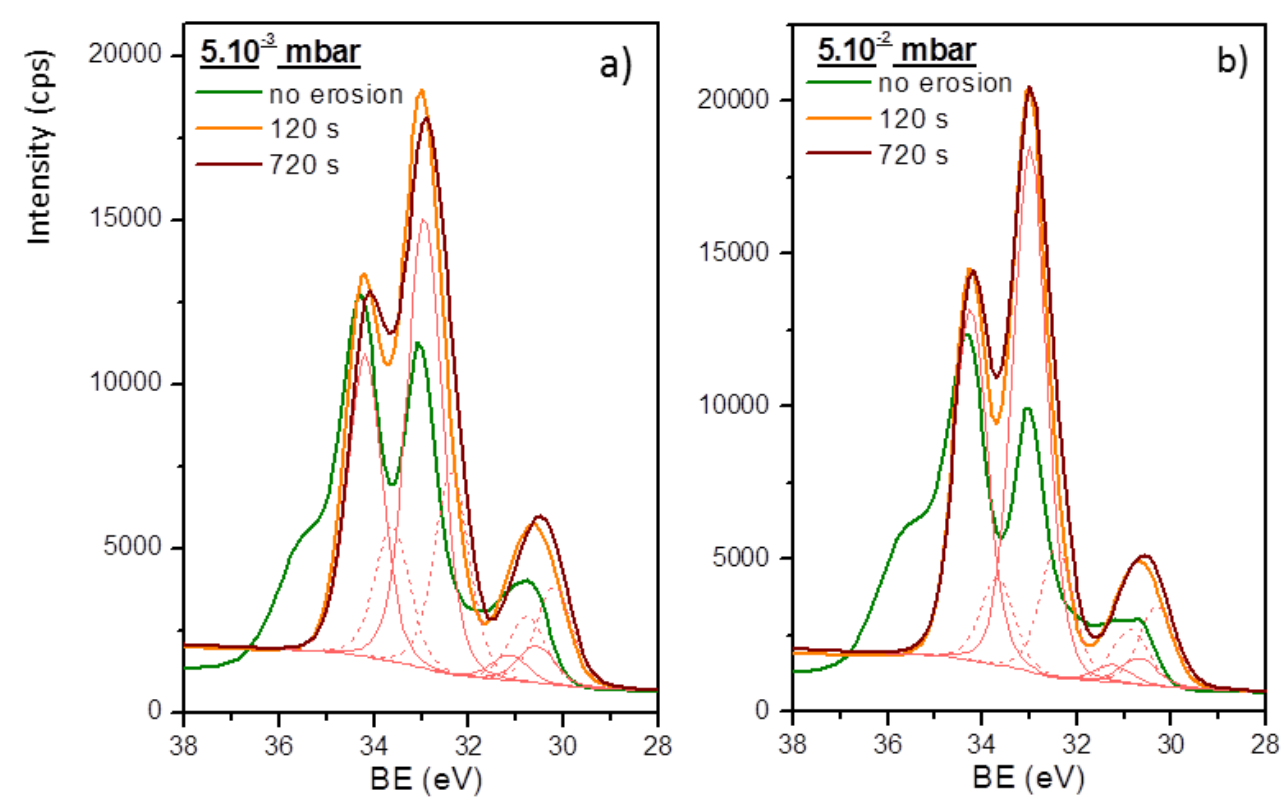

Figure 6 


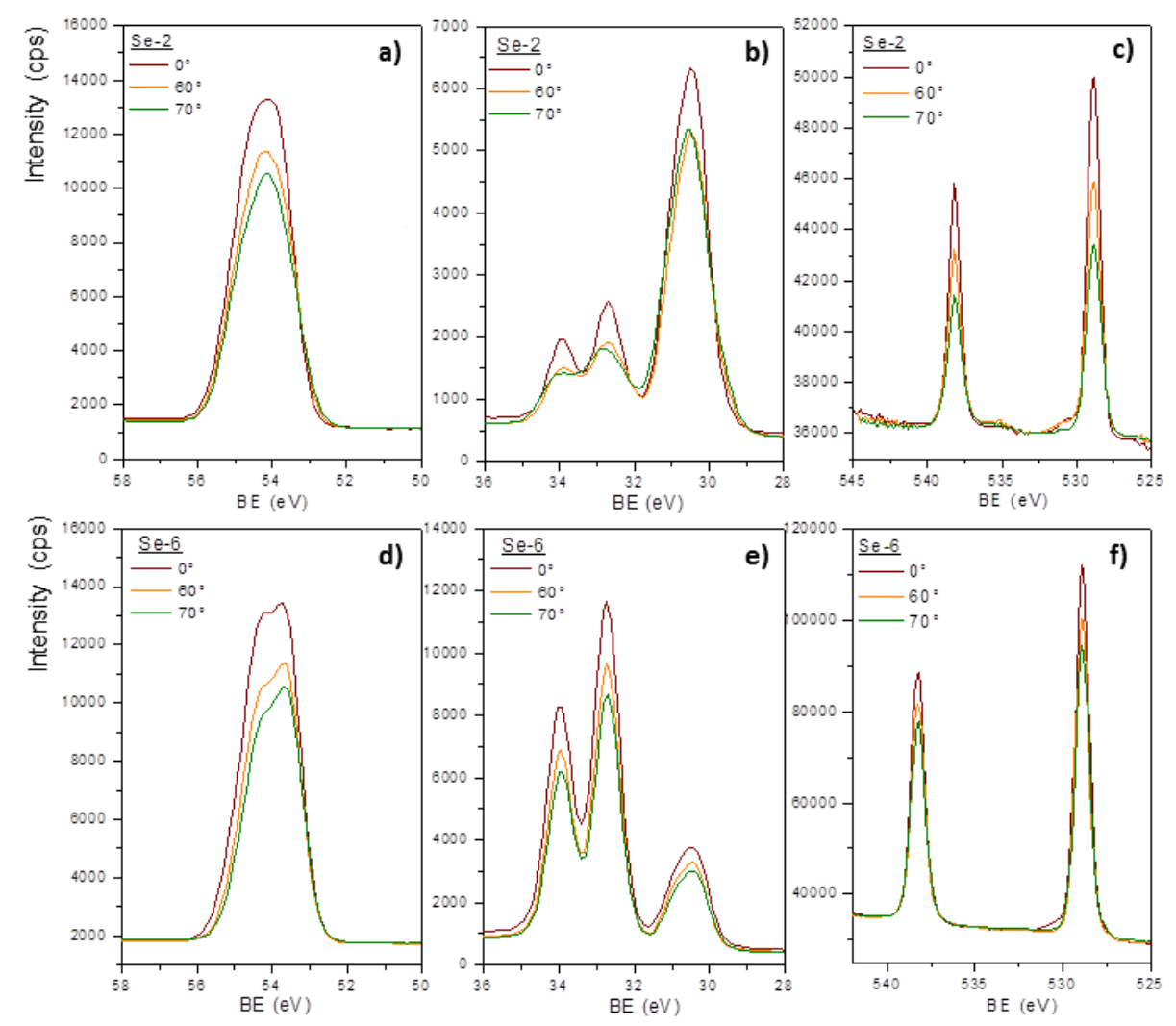

Figure 7 


\begin{tabular}{c|ccc|ccc}
\multirow{2}{*}{ Ar pressure (mbar) } & \multicolumn{2}{|c|}{$\mathbf{G e}_{\mathbf{2 8 . 1}} \mathbf{S b}_{\mathbf{6 . 3}} \mathbf{S e}_{\mathbf{6 5 . 6}}(\mathbf{S e}-\mathbf{2})$} & \multicolumn{3}{c}{$\mathbf{G e}_{\mathbf{1 2 . 5}} \mathbf{S b}_{\mathbf{2 5}} \mathbf{S e}_{\mathbf{6 2 . 5}}(\mathbf{S e}-\mathbf{6})$} \\
\cline { 2 - 7 } & $\mathbf{\% G e}$ & $\mathbf{\%} \mathbf{S b}$ & $\mathbf{\% S e}$ & $\mathbf{\% G e}$ & $\mathbf{\%} \mathbf{S b}$ & $\mathbf{\%} \mathbf{S e}$ \\
\hline Nominal composition & 28.1 & 6.3 & 65.6 & 12.5 & 25.0 & 62.5 \\
\hline Target composition & 27.6 & 5.9 & 66.5 & 12.6 & 24.5 & 62.9 \\
\hline $\mathbf{5 . 1 0}^{-3}$ & 32.7 & 6.0 & 61.3 & 15.9 & 25.9 & 58.2 \\
\hline $\mathbf{7 . 5 . 1 0}^{-3}$ & 31.7 & 5.7 & 62.6 & 15.2 & 25.1 & 59.7 \\
\hline $\mathbf{1 . 1 0}^{-2}$ & 30.2 & 6.2 & 63.6 & 11.6 & 26.4 & 62.0 \\
\hline $\mathbf{5 . 1 0}^{-2}$ & 26.9 & 5.3 & 67.8 & 13.3 & 23.0 & 63.7
\end{tabular}

Table 1 


\begin{tabular}{|c|c|c|c|c|c|c|c|c|c|c|c|c|c|}
\hline \multirow{2}{*}{ Core Level } & \multirow{2}{*}{ Species } & \multicolumn{3}{|c|}{$5.10^{-3}$ mbar } & \multicolumn{3}{|c|}{ 7.5.10 ${ }^{-3} \mathrm{mbar}$} & \multicolumn{3}{|c|}{$1.10^{-2}$ mbar } & \multicolumn{3}{|c|}{$5.10^{-2}$ mbar } \\
\hline & & BE $(e V)$ & FWHM & $\%_{\text {bonds }}$ & BE (eV) & FWHM & $\%_{\text {bonds }}$ & BE (eV) & FWHM & $\%_{\text {bonds }}$ & BE $(e V)$ & FWHM & $\%_{\text {bonds }}$ \\
\hline \multirow{2}{*}{$\operatorname{Se} 3 d_{5 / 2}$} & $\mathrm{Se}-(\mathrm{Ge}, \mathrm{Sb})_{2}$ & 53.73 & 0.89 & 85 & 53.75 & 0.87 & 85 & 53.75 & 0.86 & 86 & 53.75 & 0.91 & 68 \\
\hline & $\mathrm{Se}-\mathrm{Se}-(\mathrm{Ge}, \mathrm{Sb})$ & 54.35 & 0.89 & 15 & 54.35 & 0.87 & 15 & 54.32 & 0.86 & 14 & 54.29 & 0.91 & 32 \\
\hline \multirow{2}{*}{ Ge $3 d_{5 / 2}$} & $\mathrm{Ge}-(\mathrm{Se})_{4}$ & 30.33 & 0.80 & 78 & 30.35 & 0.80 & 90 & 30.37 & 0.80 & 88 & 30.35 & 0.80 & 95 \\
\hline & $(\mathrm{Ge}, \mathrm{Sb})-\mathrm{Ge}-(\mathrm{Se})_{3}$ & 29.84 & 0.80 & 22 & 29.94 & 0.80 & 10 & 29.96 & 0.80 & 12 & 29.80 & 0.80 & 5 \\
\hline \multirow{2}{*}{$\operatorname{Sb~} 4 d_{5 / 2}$} & $\mathrm{Sb}-(\mathrm{Se})_{3}$ & 32.73 & 0.80 & 83 & 32.73 & 0.80 & 89 & 32.73 & 0.80 & 91 & 32.71 & 0.80 & 89 \\
\hline & $(\mathrm{Ge}, \mathrm{Sb})-\mathrm{Sb}-(\mathrm{Se})_{2}$ & 32.23 & 0.80 & 17 & 32.16 & 0.80 & 11 & 32.19 & 0.80 & 9 & 32.23 & 0.80 & 11 \\
\hline
\end{tabular}

Table 2 


\begin{tabular}{|c|c|c|c|c|c|c|c|c|c|c|c|c|c|}
\hline \multirow{2}{*}{ Core Level } & \multirow{2}{*}{ Species } & \multicolumn{3}{|c|}{$5.10^{-3} \mathrm{mbar}$} & \multicolumn{3}{|c|}{ 7.5.10 ${ }^{-3} \mathrm{mbar}$} & \multicolumn{3}{|c|}{$1.10^{-2}$ mbar } & \multicolumn{3}{|c|}{$5.10^{-2}$ mbar } \\
\hline & & BE $(e V)$ & FWHM & $\%$ bonds & BE $(\mathrm{eV})$ & FWHM & $\%_{\text {bonds }}$ & $\mathrm{BE}(\mathrm{eV})$ & FWHM & $\%_{\text {bonds }}$ & $\mathrm{BE}(\mathrm{eV})$ & FWHM & $\%_{\text {bonds }}$ \\
\hline \multirow{2}{*}{$\operatorname{Se} 3 d_{5 / 2}$} & $\mathrm{Se}-(\mathrm{Ge}, \mathrm{Sb})_{2}$ & 53.50 & 1.03 & 100 & 53.57 & 0.98 & 86 & 53.52 & 0.88 & 78 & 53.50 & 0.86 & 79 \\
\hline & $\mathrm{Se}-\mathrm{Se}-(\mathrm{Ge}, \mathrm{Sb})$ & - & - & 0 & 54.32 & 0.98 & 14 & 54.10 & 0.88 & 22 & 54.06 & 0.86 & 21 \\
\hline \multirow{2}{*}{ Ge $3 d_{5 / 2}$} & $\mathrm{Ge}-(\mathrm{Se})_{4}$ & 30.26 & 0.80 & 53 & 30.30 & 0.80 & 81 & 30.34 & 0.75 & 93 & 30.30 & 0.77 & 100 \\
\hline & $(\mathrm{Ge}, \mathrm{Sb})-\mathrm{Ge}-(\mathrm{Se})_{3}$ & 29.86 & 1.05 & 47 & 29.90 & 1.23 & 19 & 29.94 & 0.70 & 7 & - & - & 0 \\
\hline \multirow{2}{*}{$\operatorname{Sb} 4 d_{5 / 2}$} & $\mathrm{Sb}-(\mathrm{Se})_{3}$ & 32.66 & 0.80 & 77 & 32.71 & 0.79 & 90 & 32.71 & 0.82 & 100 & 32.68 & 0.78 & 100 \\
\hline & $(\mathrm{Ge}, \mathrm{Sb})-\mathrm{Sb}-(\mathrm{Se})_{2}$ & 32.11 & 0.73 & 23 & 31.95 & 1.18 & 10 & - & - & 0 & - & - & 0 \\
\hline
\end{tabular}

Table 3 